\title{
The 1685 blue smalt coating of the Coimbra Old Cathedral main altarpiece under scrutiny
}

\author{
A. Le Gac*,**, I. Nogueira***, A.I. Seruya** \\ * Departamento de Conservação e Restauro, Faculdade de Ciências e Tecnologia, Universidade Nova de \\ Lisboa, 2829-516 Caparica, PORTUGAL \\ ** Centro de Física Atómica, Universidade de Lisboa, 1649-003 Lisboa, PORTUGAL \\ *** Instituto de Ciência e Engenharia de Materiais e Superfícies, Instituto Superior Técnico, Av. Rovisco Pais, \\ 1049-001 Lisboa, PORTUGAL \\ Email: $\underline{\text { alg@ fct.unl.pt }}$
}

Although smalt was used as an important pigment in European oil painting during the 16th and 17th century, records of its use in a monumental tridimensional artwork and even more in a tempera coating remain quite scarce. The main altarpiece of the Coimbra Old Cathedral is an interesting case study to shed light on the use of smalt and the trade practices of painters at the baroque period, in Portugal. The primitive colour scheme of this artwork of a Flamboyant style, achieved in 1502, was renovated during three subsequent interventions [1]. According to a historical record [2], a new polychromy was to be undertaken in 1685 by the local painter Manoel da Costa Pereira. Smalt pigment bound in oil was to be applied to the original blue surfaces, then 'burnished' to produce a polished smalt coating. A later restoration carried out in 1900 actually prevents from seeing what lies underneath.

Several micro-samples were collected in the blue background and niches of the altarpiece. They were examined by optical microscopy (MO), Scanning electron microscopy (SEM) with energy dispersive X-ray Spectroscopy (EDS) and a staining protocol, to verify if the aforesaid pigment has effectively been used and if a drying oil has been employed as binder and a mean to obtain a high reflective blue surface. All the samples cross-sections observed by OM unveiled the 1685 blue coating, always containing several grades of smalt mixed together given their more or less intense hue for grains of similar size (Figs.1-2). SEM imaging put in evidence the conchoidal fractures of the particles, specific to the blue cobalt-containing potash glass and its processing by pouring the glass paste into cold water where it disintegrated into particles for its further use as a pigment [3]. SEM-EDS analyses performed on individual grains allowed the systematic detection of $\mathrm{Si}, \mathrm{K}, \mathrm{Co}, \mathrm{Fe}$ and $\mathrm{As}$, and sometimes traces of $\mathrm{Ca}$ and $\mathrm{Al}$, except for St. Luke's niche where Co was hardly found. The Co contents (about 3-4 wt\%) are the expected ones, irrespective of the blue particles intensity [4-5], but its average of $1 \mathrm{w} \%$ in St. Luke's niche may be related to a deliberate choice by the artist to apply there a paler pigment. Ni was sometimes detected within the grains. Its presence may point the use of smaltite, $[\mathrm{Co}, \mathrm{Ni}] \mathrm{As}_{3-2}$, member of the cobalt iron nickel arsenide minerals sourced from Saxonia, or erytrite $([\mathrm{Co}, \mathrm{Ni}] 3[\mathrm{AsO} 4] 2.8(\mathrm{H} 2 \mathrm{O}))$, but its absence may also point the use of cobaltite, $(\mathrm{Co}, \mathrm{Fe}) \mathrm{AsS}$, sourced from Sweden [3,6], therefore indicating the use of marketed products of at least two origins. The very low As content, varying between $2.2 \mathrm{wt} \%$ (Virgin background) and $0.9 \mathrm{wt} \%$ (St. Luke and Paul's niches) suggests the cobalt ore was calcined so as to eliminate volatile compounds such as arsenic. Although the transparent particles of smalt were coarsely ground (the largest one measuring the impressive $64 \mu \mathrm{m}$ across) to overcome their low hiding power, an unexpected result came out by OM and SEM-EDS giving evidence of the use of lead-based light blue and pink underlayers (Figs. 1-2) to give the final blue smalt coating more intense and subtle shades. Micro-chemical analyses carried out on cross-sections with a staining protocol (acid fuchsin and rhodamine B dyes) showed confusing results regarding the binder. It seems that smalt was bound with a proteinaceous substance stained red by acid fuchsin, such as parchment or animal glue, likely to prevent the pigment from being altered by the yellowing of a drying oil. The gelatinous nature of the binding medium kept the particles clearly suspended until the paint became dry. A final oil film might have been soon applied 
to ensure a final glossy effect since oil was also detected by rhodamine B within the paint. These results may fit a 1620 Turquet de Mayerne's recipe [1] which is actually being tested by a historical accurate reconstitution. The role the oil medium might have play on a potential leaching of smalt alkaline components [4-6], ie a depletion of potassium ions around cobalt responsible for the particles discoloration [7], requires further research.

[1] Le Gac A., PhD thesis, Universidade Nova de Lisboa, 2009.

[2] Louro J.M.S., Mundo da Arte, 13:60-63, 1983.

[3] Mühlethaler B. and Thissen J., Studies in Conservation, 14:62-74, 1969.

[4] Spring M. et al., National Gallery Technical Bulletin, 26:56-70, 2005.

[5] Santopadre P. and Verità M., Studies in Conservation, 51:29-40, 2006

[6] Stege H., Zeitschrift fur Kunsttechnologie und Konservierung, 18:121-142, 2004.

[7] Robinet L. et al., ICOM-CC 16th Triennial Meeting Preprints, Lisbon, p.1-8, 2011.

A. Le Gac acknowledges FCT for the grant PTDC/EAT-EAT/116700/2010 - GILT-Teller.
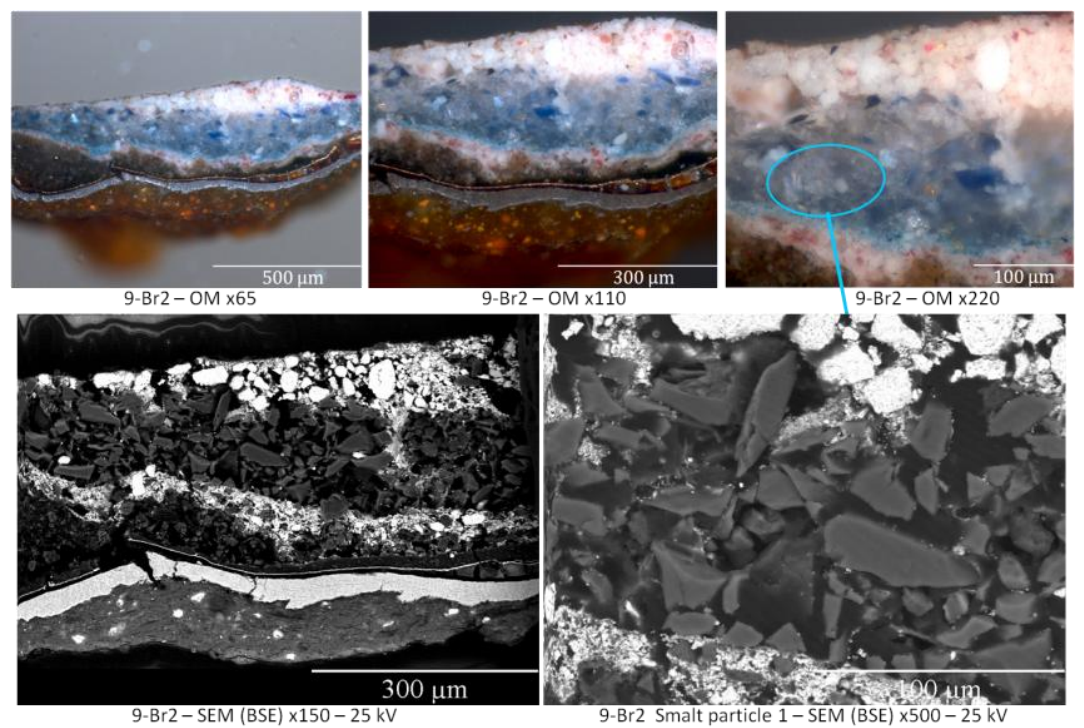

Figure 1. The 1685 blue smalt coating of the altarpiece of the Coimbra Old Cathedral (Portugal) unveiled by OM and SEM imaging in the multilayer structure of sample 9-Br2
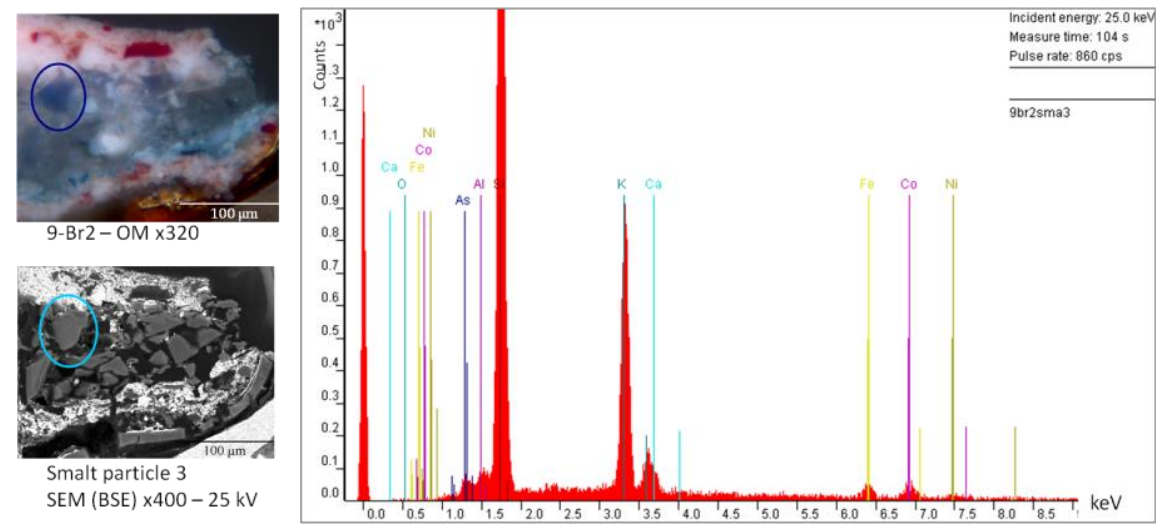

Figure 2. SEM-EDS analysis of a blue smalt particle containing $\mathrm{Si}, \mathrm{K}, \mathrm{Co}, \mathrm{Fe}, \mathrm{As}$ and Ni 